\title{
A formalin fixative for immunochemical and ultrastructural studies on gastrointestinal endocrine cells
}

\author{
GRAHAM ROBINSON AND IAN DAWSON
}

From the Department of Pathology, University Hospital, Queen's Medical Centre, Nottingham, NG7 2UH, $U K$

SUMMARY Using indirect immunofluorescence, indirect immunoperoxidase, and unlabelled antibody enzyme techniques, gastrin, pancreatic glucagon, insulin, and somatostatin were localised in sections of both wax- and resin-embedded tissues that had been fixed in a buffered formalin solution. Ultrastructural preservation of the resin-embedded samples was also adequate for combined electron microscopy and light microscope immunochemistry. As the fixative concerned is stable it can be permanently available in surgical units. It is suggested, therefore, that this fixative should prove useful as an alternative to buffered formaldehyde, which must be freshly prepared from paraformaldehyde powder, in institutions where specimen collection is difficult or which have to refer cases with an endocrine involvement to other laboratories for immunochemical and fine structural examination.

The retention of the immunological activity of antigenic determinant sites of polypeptides in satisfactorily preserved tissue is a major problem in the immunochemical demonstration of cells containing specific gastrointestinal hormones. At the light microscope level, many hormones require special fixatives if reactive antigenic sites are to be retained, while others require freeze-drying and vapour-fixation with bifunctional reagents (Pearse and Polak, 1975). This latter form of tissue preparation gives adequate preservation for light microscopy but is unsuitable for electron microscopy, for which buffered glutaraldehyde is preferred. This usually means either that a number of samples must be taken at operation and processed so that both light and electron microscopy can be undertaken, or that investigations are less than complete. For some hormones, this is inevitable; for others it is not so. The antigenic determinants of several hormones are adequately preserved in fixatives prepared from paraformaldehyde powder, and tissues so preserved are also suitable for electron microscopy. However, prior notice of surgery is necessary as the fixative must be freshly prepared. Since, in many hospitals, this can give rise to problems in obtaining suitably fresh specimens

Received for publication 26 June 1978 for fixation, this study was initiated to see if there was available a fixative that was, firstly, stable enough to be left permanently in the operating suite and, secondly, suitable for both immunochemical and fine structural examination of tissue samples.

One possible fixative is the stable phosphatebuffered formalin fixative introduced by Carson et al. (1973). This fixative is reported to be suitable for both conventional light and electron microscopy, and as it is stable advance knowledge of operation or preselection of tissue samples immediately after excision is not necessary. We therefore used it as the basis for our immunochemical studies on peptide hormones.

\section{Material and methods}

At operation biopsy and excised surgical specimens were fully immersed in approximately 15 times their volume of Carson's fixative and were then stored at $4^{\circ} \mathrm{C}$ to await collection. Hollow viscera were cut open by theatre staff before immersion so that mucosal surfaces were exposed to fixative solution; biopsy specimens were placed directly into fixative. After collection, samples of the size required for subsequent light and electron microscope investigations were taken and re-immersed in 
fresh precooled $\left(4^{\circ} \mathrm{C}\right)$ Carson's fixative for further fixation. Total times in fixative solution varied from four hours for biopsy specimens to eight to 24 hours maximum for larger specimens.

The fixative was prepared essentially as Carson et al. (1973) described.

MODIFIED MILLONIG'S PHOSPHATE-BUFFERED FORMALIN (Carson et al., 1973)

1 Add $18.6 \mathrm{~g}$ sodium dihydrogen orthophosphate $\left(\mathrm{NaH}_{2} \mathrm{PO}_{4} 2 \mathrm{H}_{2} \mathrm{O}\right)$ and $4.2 \mathrm{~g}$ sodium hydroxide $(\mathrm{NaOH})$ to approximately $800 \mathrm{ml}$ distilled water and stir until the solid dissolves.

2 Make up to $900 \mathrm{ml}$ with distilled water and then add $100 \mathrm{ml} 36 \%$ formaldehyde solution (technical grade).

The $\mathrm{pH}$ of the final fixative solution is in the range $\mathrm{pH} 7.2$ to $7 \cdot 4$, and the osmolarity of the buffer vehicle, that is, the salts dissolved in the distilled water, approximately $290 \mathrm{mmol} / \mathrm{kg}$.

After fixation, all tissue samples were washed for a total of three hours in three separate changes of 0.12 M Millonig's phosphate buffer wash, $\mathrm{pH} 7 \cdot 2$, containing 3\% sucrose (Robinson, 1977). Tissue for light microscopy was then processed to $56^{\circ} \mathrm{C}$ melting point paraffin wax, while samples for electron microscopy were post-fixed for 90 minutes in Millonig's phosphate-buffered $1 \%$ osmium tetroxide (Millonig, 1962), dehydrated in ethanol, and embedded in Araldite resin.

For light microscope immunochemistry, wax sections were cut at $5 \mu \mathrm{m}$. For combined light microscope immunochemistry and electron microscopy, the semithin-thin technique of Polak et al. (1975) was used. With this technique a $1-\mu \mathrm{m}$ section is cut from the resin block and mounted on a glass slide, and then several sequential ultrathin sections are cut from the same block face and picked up on grids; the $1-\mu \mathrm{m}$ resin section is used for light microscope immunochemistry and the ultrathin sections for conventional transmission electron microscopy. Before staining, the $1-\mu \mathrm{m}$ resin sections were etched for two minutes in a sodium methoxide/benzene solution diluted 1:2 with a mixture of equal parts methyl alcohol and benzene, thoroughly rinsed in methyl alcohol/ benzene $(1: 1)$ and then in absolute acetone, and finally rehydrated to water (Mayor et al., 1961). The sequential ultrathin sections were cut at $60 \mathrm{~nm}$, mounted on copper grids, double stained with uranyl acetate and lead citrate, and viewed in a Phillips EM 300 electron microscope.

Antisera to gastrin, insulin, pancreatic glucagon, and somatostatin (all kindly provided by Professor K. D. Buchanan, Department of Medicine, Queen's University of Belfast) were fractionated to the globulin component using ammonium sulphate precipitation (Sternberger, 1974). After dialysis the total protein content of the fraction was subsequently adjusted to give $5 \mathrm{mg}$ total protein $/ \mathrm{ml}$ of dialysate. The specificity of the antisera was tested using immunoelectrophoresis and the double gel diffusion method of Ouchterlony. For immunochemistry, all the antisera were diluted 1:20 with Tris-saline containing $1 \%$ normal swine serum.

Swine anti-rabbit IgG, peroxidase-conjugated and fluorescein isothiocyanate (FITC)-conjugated swine anti-rabbit IgG, soluble complex of horseradish peroxidase (HRP) rabbit anti-horseradish peroxidase (PAP), and normal swine serum were all obtained commercially from Mercia Brocades Ltd. For immunochemistry, the antisera were diluted with Tris-saline containing $1 \%$ normal swine serum as follows: (a) swine anti-rabbit IgG-FITC 1:16; (b) swine anti-rabbit IgG and swine anti-rabbit IgG-HRP 1:20; and (c) PAP $1: 60$.

The immunochemical staining techniques used were indirect fluorescence, indirect immunoperoxidase, and the unlabelled antibody enzyme method (Sternberger, 1974; Burns, 1975; Petrusz et al., 1975).

All incubations were undertaken at room temperature in moist incubation chambers, washes between incubations were carried out with Tris-saline (Erlandsen et al., 1974), and the peroxidase tracer was visualised by DAB cytochemistry (Graham and Karnovsky, 1966).

If necessary, endogenous peroxidase activity was inhibited by pretreatment of the section with methanol/hydrogen peroxide (Burns, 1975) or distinguished from tracer-derived peroxidase by use of a double staining technique (Robinson and Dawson, 1975).

Control sections were incubated with each test and included specificity controls, blocking controls, and neutralising controls, which used anti-hormone sera that had been absorbed with excess antigen before use in the relevant staining schedule (McGuigan, 1968).

FITC-stained preparations were mounted and viewed without further treatment, wax-embedded peroxidase preparations were counterstained with PAS/haematoxylin, and resin-embedded peroxidase preparations were counterstained in $1 \%$ osmium tetroxide for five minutes, washed in running water, and then stained with toluidine blue.

\section{Results}

At the light microscope level, gastrin, pancreatic glucagon, insulin, and somatostatin could all be 


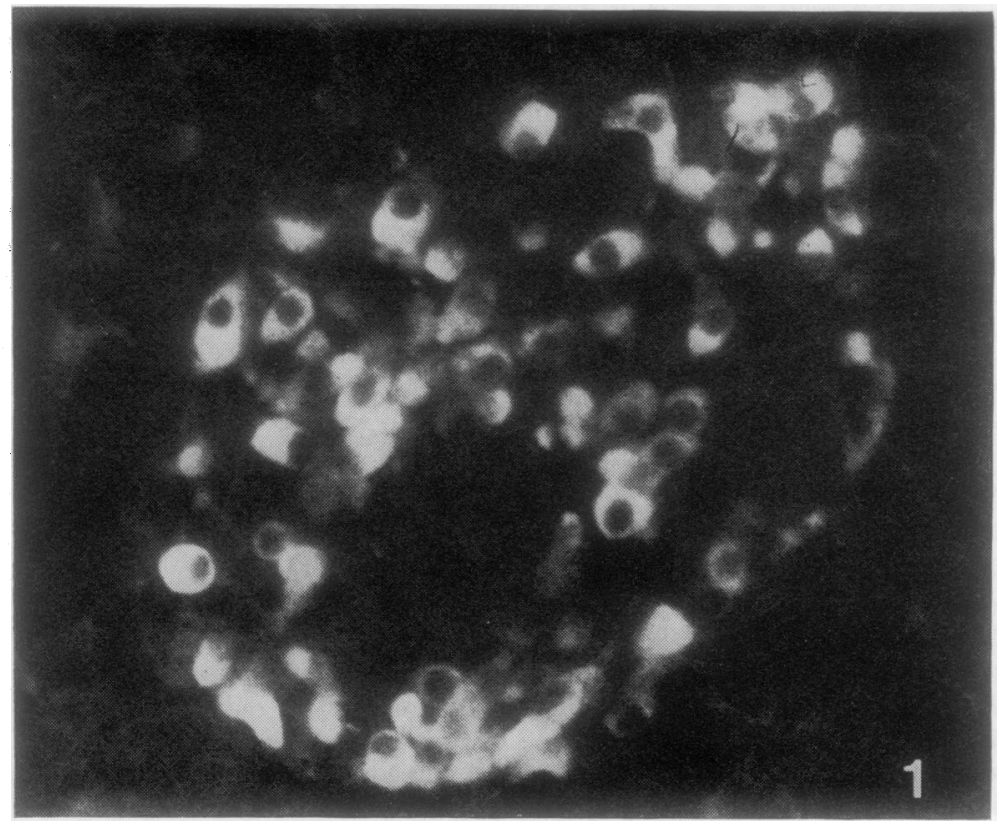

Fig. 1 Glucagon-containing cells in human pancreatic islets. Wax-embedded specimen stained by indirect immunofluorescence. $\times 1170$

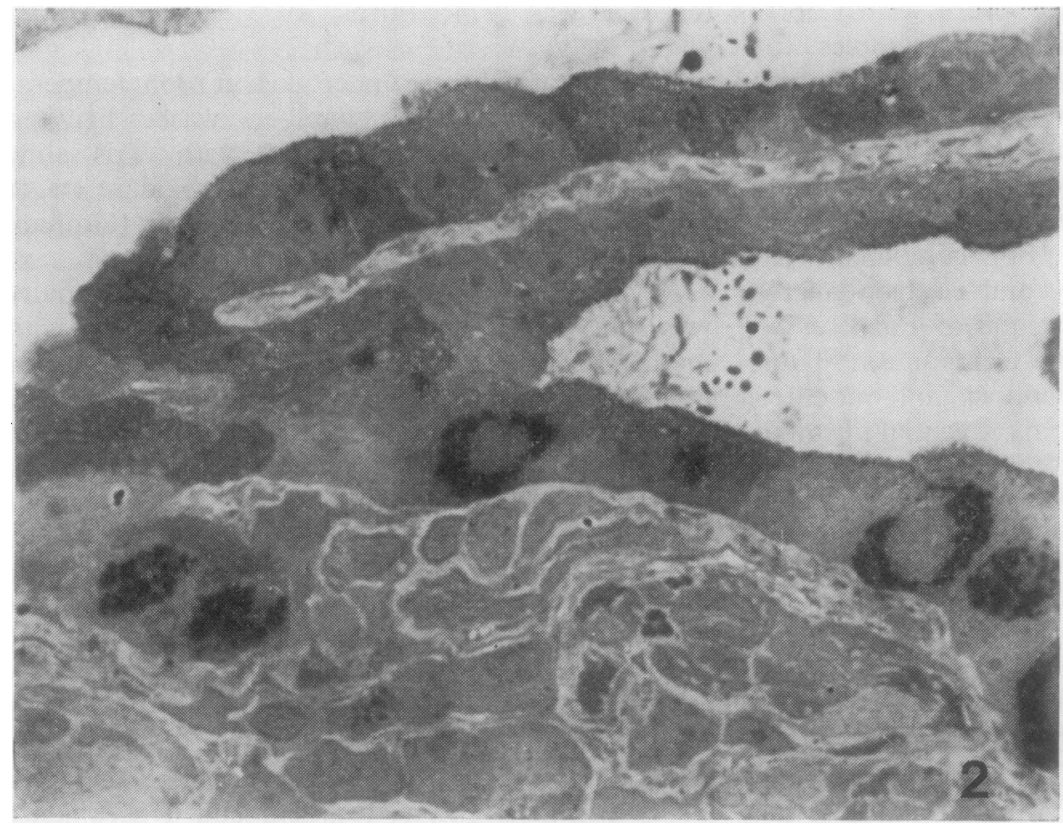

Fig. 2 Gastrin-containing cells in human pyloric antrum. Resin-embedded specimen stained by the unlabelled antibody enzyme method. $\times 1170$

localised in sections of paraffin-embedded tissue with all the staining techniques used (Fig. 1). With etched $1-\mu \mathrm{m}$ resin sections similar results were obtained, but the reaction end product of the PAP method was generally more intense than that obtained with either of the indirect techniques
(Fig. 2). Etching was an essential step in staining procedures with resin sections as untreated sections were not properly stained. Although sodium methoxide/benzene solution used at full strength for one minute caused some disruption of resin sections, diluted etching solution used for two 


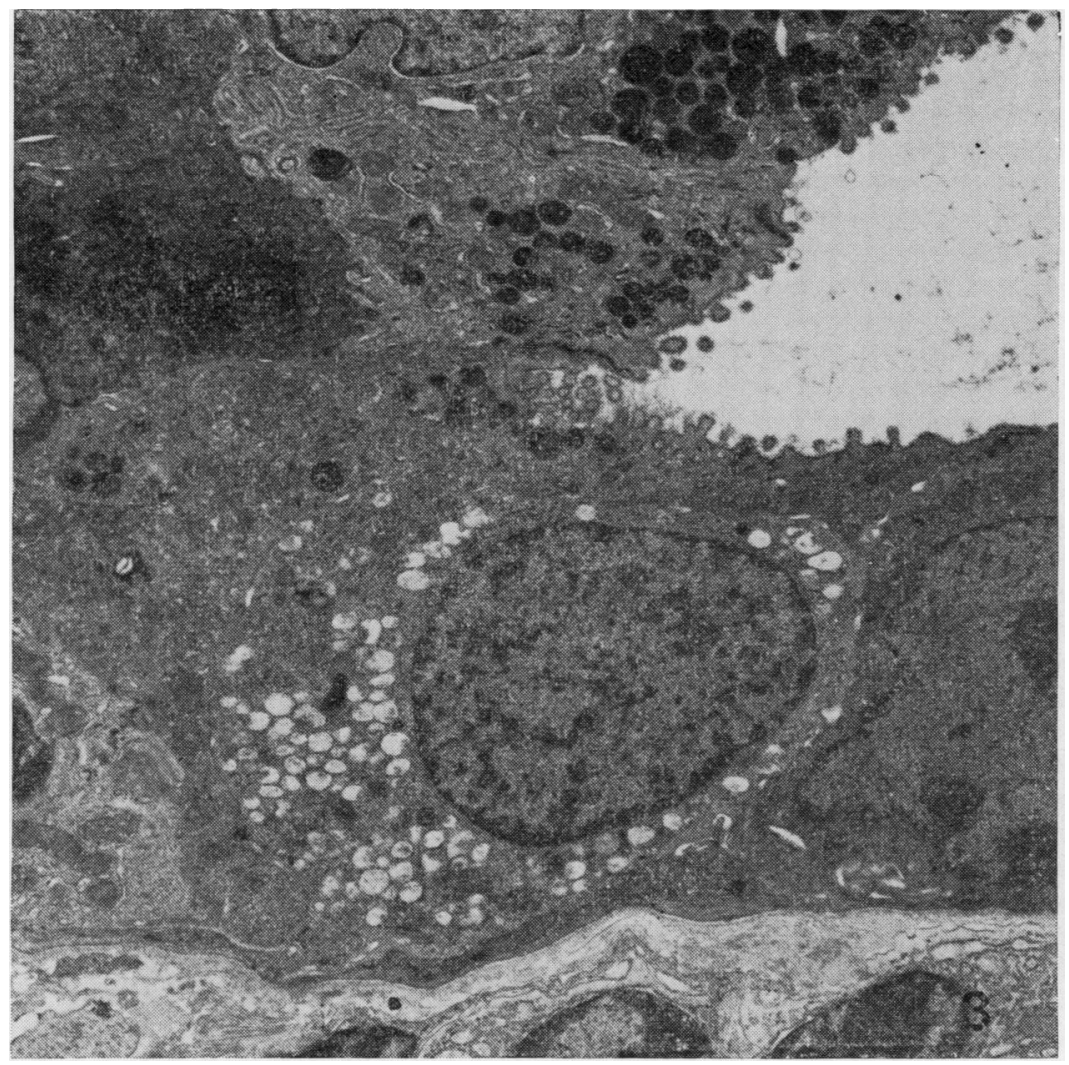

Fig. 3 Gastrin-containing cell in sequential ultrathin section of area shown in Fig. 2. $\times 5600$

minutes had no adverse effect upon the integrity of sections.

Nonspecific background staining was minimal when the sections had been pretreated for 10 minutes with Tris-saline containing $10 \%$ normal swine serum before application of the first immune serum. This pretreatment blocks the cationic sites, which are responsible for nonspecific background staining (Hardy et al., 1970).

There were no positively staining cells in specificity and neutralising control sections. In blocking controls, some positive staining was present but the intensity of the reaction end product was minimal when compared with that of positive cells in test sections.

Fine structural preservation of tissues, although not as good as that in glutaraldehyde-fixed tissue, was adequate for the semithin-thin technique to be used successfully (Figs. 2 and 3 ). The most noticeable fixation artifacts at the fine structural level were slight increases in width of some intercellular spaces within the gastric epithelium and a more pronounced separation between the fibrous connective tissue elements in the lamina propria, especially in the area abutting the basement membrane of the mucosa (Fig. 4).

\section{Discussion}

In terms of tissue preservation for subsequent immunochemistry, the endocrine cells of the gastroenteropancreatic tract can be divided into two groups. One group contains cells that elaborate hormones, such as GIP and VIP, whose antigenic determinants can be satisfactorily preserved only in tissue that has been snap-frozen, freeze-dried, and then vapour-fixed in a bifunctional reagent (Pearse and Polak, 1975). The second group of cells elaborate hormones, such as the ones included in this study, that can be localised without apparent loss of antigenicity in buffered formaldehyde freshly generated from paraformaldehyde powder. With both classes of hormones, because of the fixative methods to be used, advance knowledge of surgery is necessary. For diagnostic and research laboratories which are near the operating suite this causes no serious problems. However, when laboratories are some distance away from the 


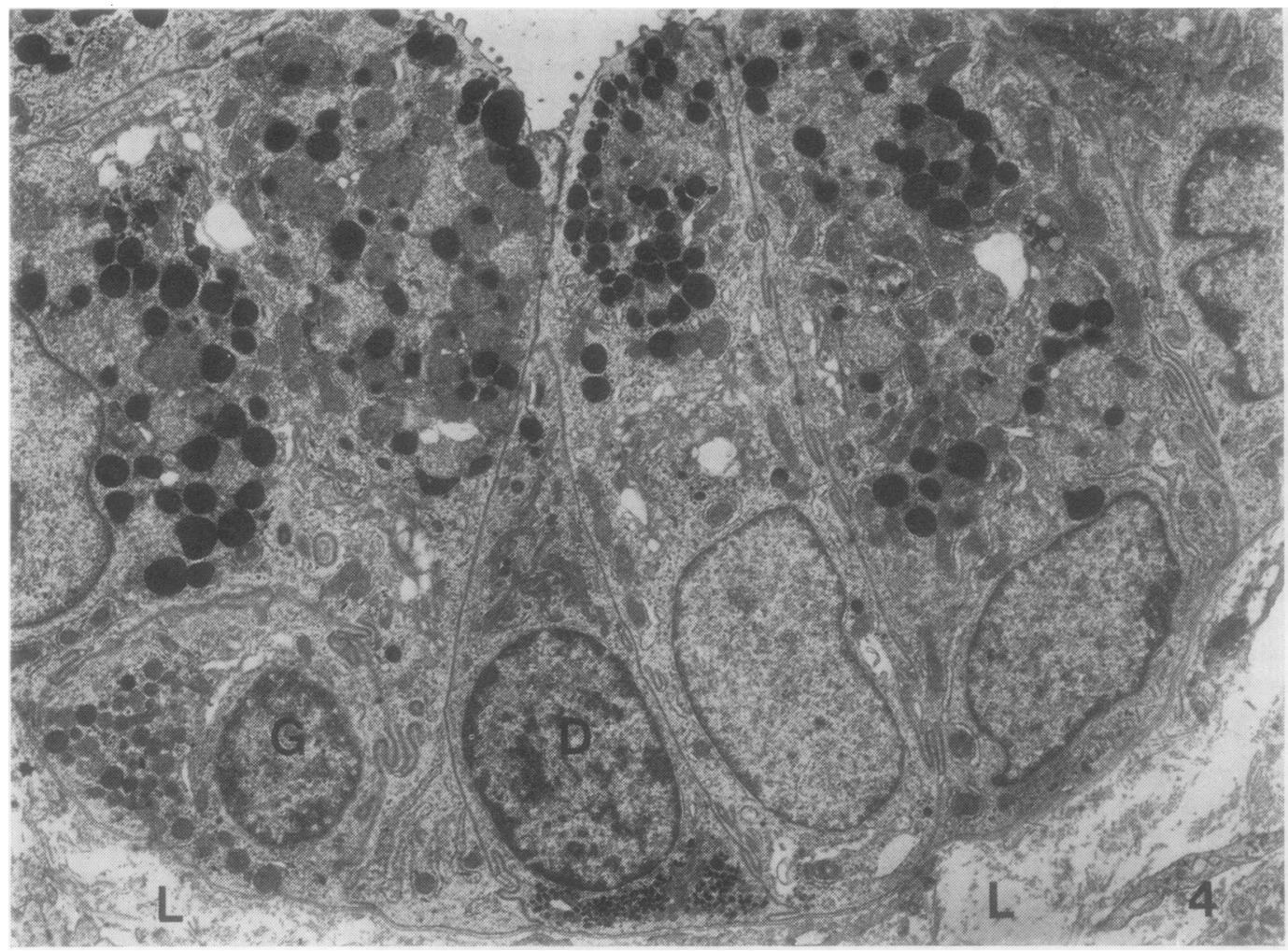

Fig. 4 Gastrin-containing cell $(G)$ with well-filled granules and a somatostatin-containing cell $(D)$ in human pyloric antrum. L, lamina propria. $\times 3920$

surgical unit the collection of suitably fresh specimens for fixation for special procedures is often difficult and time-consuming, and many specimens are unavoidably air-dried before immersion in fixative. This study was initiated, therefore, to see if there was available a stable fixative for preserving those cells normally fixed in freshly prepared buffered formaldehyde.

The results show that the buffered formalin fixative introduced by Carson et al. (1973) meets the necessary criteria of being stable and suitable for both light microscope immunochemistry and conventional transmission electron microscopy. Comparative immunochemical studies using tissue fixed in freshly prepared buffered formaldehyde and tissue fixed in Carson's buffered formalin have shown that the fluorescent and enzyme reaction end products are of similar intensity. While at the fine structural level, although freshly prepared buffered formaldehyde, that is, fixative less than 24 hours old, gives superior ultrastructural preservation to Carson's formalin fixative, when fixatives over 5 days old are used the quality of fine structural preservation is usually better in Carson's fixed tissue than in buffered formaldehydefixed tissue (Robinson, unpublished observations).

Although it is preferable to renew the fixative each week, 3-month-old Carson's fixative will still allow good immunochemical staining and produce adequate fine structural preservation (Robinson, 1977).

Carson's fixative should also prove useful in those hospitals that do not have on site facilities for immunochemistry and electron microscopy. Usually referred specimens have been fixed in formol saline, and although immunochemistry is possible with such tissue the results are often poor and inconclusive. Fine structural preservation of such fixed wet samples is also inadequate and, when the samples provided have been embedded in paraffin wax, ultrastructural preservation of tissue removed from the block and reprocessed for electron microscopy is generally too poor to be of value.

If a supply of Carson's fixative is kept in the operating suite it will also prevent the loss of 
suitable tissue which is resected at operations undertaken out of normal laboratory hours.

Our thanks are due to those surgeons in the General Hospital in Nottingham, especially Mr J. Bourke, who allowed us to use material from their cases, and to Professor K. D. Buchanan for generous gifts of antisera.

This work was supported by a grant from the Cancer Research Campaign, to whom we are greatly indebted.

\section{References}

Burns, J. (1975). Background staining and sensitivity of the unlabelled antibody-enzyme (PAP) method. Comparison with the peroxidase labelled antibody sandwich method using formalin fixed paraffin embedded material. Histochemistry. 43, 291-294.

Carson, F. L., Martin, J. H., and Lynn, J. A. (1973). Formalin fixation for electron microscopy: a reevaluation. American Journal of Clinical Pathology, 59, 365-373.

Erlandsen, S. L., Parsons, J. A., and Taylor, T. D. (1974). Ultrastructural immunocytochemical localisation of lysozyme in the Paneth cells of man. Journal of Histochemistry and Cytochemistry, 22, 401-413.

Graham, R. C., Jr., and Karnovsky, M. J. (1966). The early stages of absorption of injected horseradish peroxidase in the proximal tubules of mouse kidney: ultrastructural cytochemistry by a new technique. Journal of Histochemistry and Cytochemistry, 14, 291302.

Hardy, P. H., Petrali, J. P., and Sternberger, L. A. (1970). Postembedding staining for electron microscopy by the unlabeled antibody enzyme method. (Abstract). Journal of Histochemistry and Cytochemistry, 18, 678 .

Mayor, H. D., Hampton, J. C., and Rosario, B. (1961).
A simple method for removing the resin from epoxyembedded tissue. Journal of Biophysical and Biochemical Cytology, 9, 909-910.

McGuigan, J. E. (1968). Gastric mucosal intercellular localization of gastrin by immunofluorescence. Gastroenterology, 55, 315-327.

Millonig, G. (1962). Further observations on a phosphate buffer for osmium solutions in fixation. In 5th International Congress in Electron Microscopy, edited by S. S. Breese, Volume 2, p. 8. Academic Press, New York and London.

Pearse, A. G. E., and Polak, J. M. (1975). Bifunctional reagents as vapour- and liquid-phase fixatives for immunochemistry. Histochemical Journal, 7, 179-186.

Petrusz, P., DiMeo, P., Ordronneau, P., Weaver, C., and Keefer, D. A. (1975). Improved immunoglobulinenzyme bridge method for light microscopic demonstration of hormone-containing cells of the rat adenohypophysis. Histochemistry, 46, 9-26.

Polak, J. M., Pearse, A. G. E., and Heath, C. M. (1975). Complete identification of endocrine cells in the gastrointestinal tract using semithin-thin sections to identify motilin cells in human and animal intestine. Gut, 16, 225-229.

Robinson, G. (1977). Electron microscopy: principles of electron microscopy and tissue preparation. In Theory and Practice of Histological Techniques, edited by $\mathrm{J}$. D. Bancroft and A. Stevens, Chapter 20, p. 326. Churchill Livingstone, Edinburgh and London.

Robinson, G., and Dawson, I. (1975). Immunochemical studies on the endocrine cells of the gastrointestinal tract. I. The use and value of peroxidase-conjugated antibody techniques for the localisation of gastrincontaining cells in the human pyloric antrum. Histochemical Journal, 7, 321-333.

Sternberger, L. A. (1974). Immunocytochemistry. PrenticeHall, Inc., Englewood Cliffs.

Requests for reprints to: Dr G. Robinson, Department of Pathology, University Hospital, Queen's Medical Centre, Nottingham, NG7 2UH, UK. 